\title{
Dispersal in male ursine colobus monkeys (Colobus vellerosus): influence of age, rank and contact with other groups on dispersal decisions
}

\author{
Julie A. Teichroeb ${ }^{1)}$, Eva C. Wikberg \& Pascale Sicotte \\ (Department of Anthropology, University of Calgary, 2500 University Drive N.W., Calgary, \\ $\mathrm{AB}$, Canada T2N 1N4)
}

(Accepted: 29 April 2011)

\begin{abstract}
Summary
Dispersal is male-biased in ursine colobus monkeys (Colobus vellerosus), although female dispersal also occurs (Teichroeb et al., 2009). Here we describe the process of male dispersal and its connection with between-group encounters (BGEs, $N=444$ ) and male incursions (when males left their group and approached within $50 \mathrm{~m}$ of another group; $N=128$ ) at the Boabeng-Fiema Monkey Sanctuary in central Ghana. Through BGEs and incursions, particularly those with non-aggressive interactions between individuals in different groups (BGEs, $N=17$; incursions, $N=4$ ), males could probably assess other groups for dispersal opportunities. There was a trend for males to perform incursions more frequently before emigrating voluntarily than involuntarily. Incursions were often performed towards the group that the male eventually transferred to. Incursions by alpha males were temporally shorter and more aggressive than those by non-alpha males. We suggest that non-alpha males used incursions to assess other groups for breeding or dispersal opportunities, whereas alpha males performed incursions mainly to convey information about their quality to neighbouring males and females. Male emigrations/disappearances (natal $N=20$, secondary $N=43$, unknown $N=9$ ) and immigrations $(N=62)$ were recorded for seven groups during ten years (20002010). Alpha males always emigrated involuntarily. Parallel emigration and immigration occurred. Males often immigrated into groups with a more favourable adult male/adult female ratio and improved their rank, both of which likely increased their mating opportunities. The most fitting ultimate explanation for both natal and secondary male dispersal in this population was the intrasexual competition for mates hypothesis, as males of all ages appeared to emigrate to improve their reproductive opportunities.
\end{abstract}

Keywords: Male emigration, male immigration, male dispersal, parallel dispersal, female group size, between-group encounters, male incursions, male forays, dispersal decisions.

1) Corresponding author's e-mail address: jateichr@ucalgary.ca 


\section{Introduction}

Our understanding of dispersal patterns in animals is ever increasing, especially with respect to sex differences in dispersal probability and distance (Clutton-Brock \& Sheldon, 2010) and the proximate and ultimate explanations for dispersal (Johnson \& Gaines, 1990; Smale et al., 1997). However, for long-lived, social species like primates it is rare to have data on the events before and after dispersal (but see: Gould, 2006; Ekernas \& Cords, 2007; Stoinski et al., 2009) or long-term life history information for the dispersing sex throughout more than one transfer (but see Sussman, 1992; Alberts \& Altmann, 1995; Okamoto et al., 2000; Jack \& Fedigan, 2004a,b).

In mammals, natal and secondary dispersal are male-biased (Greenwood, 1980). Before leaving their resident group, males may assess other groups for dispersal opportunities. They can evaluate other groups during betweengroup encounters (BGEs, e.g., Steenbeek, 1999; Sicotte \& MacIntosh, 2004) or they can use male incursions (sometimes called forays) to 'visit' or 'sample' a group before immigrating. These incursions involve males leaving their resident group, approaching, and sometimes integrating into other groups. Male incursions allow assessment of neighbouring groups for dispersal or breeding opportunities (e.g., mammals: Otaria byronia, Campagna et al., 1988; Suricata suricatta, Doolan \& Macdonald, 1996; Young et al., 2007; Chlorocebus aethiops, Cheney \& Seyfarth, 1983; Colobus vellerosus, Sicotte \& MacIntosh, 2004; C. polykomos, Korstjens et al., 2005; birds: reviewed in Westneat \& Stewart, 2003). Through these interactions males can gauge possible resistance to their immigration and the number of females that may be reproductively active. Incursions may also convey information about male quality (e.g., mammals: Gorilla beringei beringei, Watts, 1994; Presbytis thomasi, Steenbeek, 1999; C. vellerosus, Sicotte \& MacInstosh, 2004). Where female dispersal also occurs, males may use incursions to display their strength to entice females to transfer to their group (e.g., G. $b$. beringei, Watts, 1994; P. thomasi, Steenbeek, 1999). In species with bisexual dispersal, where both males and females can integrate into existing social units, whether incursions are primarily used to assess other groups for dispersal opportunities or entice female transfer may depend on the rank or life-stage of the male(s) (Steenbeek, 1999).

The competitive ability and/or condition of males may determine the timing of emigration and the strategies used to enter a new group or territory 
(e.g., mammals: Mirounga angustirostris, Le Boeuf \& Reiter, 1988; Macaca fascicularis, van Noordwijk \& van Schaik, 2004; Odocoileus virginianus, McCoy et al., 2005; Papio hamadryas ursinus, Clark et al., 2008; Ctenodactylus gundi, Nutt, 2008; birds: Phoenicopterus ruber roseus, Barbraud et al., 2003; reptiles: Lacerta vivipara, Meylan et al., 2002). Male primates can enter groups using relatively little aggression and start at the bottom of the male hierarchy (e.g., M. mulatta, Drickamer \& Vessey, 1973; M. fuscata, Sugiyama \& Ohsawa, 1975; Chlorocebus aethiops, Henzi \& Lucas, 1980) or they can immediately challenge the dominant males and attempt to take over the group, evicting the resident males (e.g., Presbytis johnii, Poirier, 1970; M. fascicularus, van Noordwijk \& van Schaik, 1985; Alouatta seniculus, Agoramoorthy \& Rudran, 1993; Semnopithecus entellus, Borries, 2000).

Dispersal is a risky endeavour for animals at any life-stage. For males, the most prominent dangers are greater predation risk while between groups and increased conspecific aggression when attempting to enter new groups (Pusey \& Packer, 1987a; Isbell \& Van Vuren, 1996; Isbell, 2004). Males may also lose allies when they move between groups. These risks are tolerated because dispersal can improve mating opportunities (Shields, 1987; Pusey, 1992). Males can move to a group or area with more receptive females (e.g., mammals: Papio anubis, Packer, 1979; Lemur catta, Sussman, 1992; Ursus arctos, Krofel et al., 2010), a more favourable adult sex ratio (e.g., mammals: P. cynocephalus, Alberts \& Altmann, 1995; Cebus capucinus, Jack \& Fedigan, 2004b; Meles meles, Macdonald et al., 2008; L. catta, Parga \& Lessnau, 2008; birds: Perisoreus infaustus, Griesser et al., 2008), or where they can increase their rank relative to their original group (e.g., mammals: Chlorocebus aethiops, Cheney \& Seyfarth, 1983; P. cynocephalus, Smith, 1992; Cebus capucinus, Jack \& Fedigan, 2004b; birds: Passer domesticus, Altwegg et al., 2000; Melospiza melodia, Arcese, 1989). However, dispersing males do not always improve their breeding opportunities in the short term (e.g., Chlorocebus aethiops, Cheney, 1983; L. catta, Sussman, 1992; S. entellus, Borries, 2000; Papio hamadryas ursinus, Clarke et al., 2008; G. b. beringei, Stoinski et al., 2009).

Some of the costs associated with dispersal can be mitigated by parallel dispersal, which involves transferring with other group members or into groups with familiar individuals (van Hooff, 2000). Parallel dispersal has three main benefits: (1) it might reduce predation risk for males while they are between groups; (2) males may avoid the loss of allies; and (3) they may 
be able to more easily overcome the resistance of residents with the assistance of allies (Schoof et al., 2009). Some males even continue to reside with kin despite transferring between groups when they disperse with members of their age-cohort (potentially full or half siblings) or their father/son (Altmann, 1979; Cheney, 1983; van Hooff, 2000; Jack \& Fedigan, 2004a,b).

The two main ultimate hypotheses for male dispersal are: (1) inbreeding avoidance, which may explain not only natal dispersal (Itani, 1972; Packer, 1979; Pusey, 1987; Clutton-Brock, 1989) but also secondary dispersal if the male resides with maturing daughters (Pusey \& Packer, 1987b); and (2) intrasexual competition for mates, which may explain male secondary (or breeding) dispersal (Henzi \& Lucas, 1980; Dobson, 1982; Moore \& Ali, 1984; Pusey \& Packer, 1987a; Alberts \& Altmann, 1995; Jack, 2003). Male competitors can come from both inside and outside the group, and losing contests to immigrant males can lead to involuntary emigration from the group or territory (e.g., mammals: Cebus capucinus, Jack \& Fedigan, 2004b; insects: Pachydiplax longipennis, McCauley, 2010). Hence, males are forced to emigrate again and may have to immigrate into a new group (secondary dispersal). Males may also emigrate due to predation risk (Isbell \& Van Vuren, 1996) or food competition, though food competition is more likely to cause female dispersal (Trivers, 1972; van Schaik, 1989).

In this paper, we describe male emigrations/disappearances and immigrations in seven groups of ursine colobus (Colobus vellerosus) at the BoabengFiema Monkey Sanctuary in Ghana during ten years of research. This is the first detailed study on the process and outcomes of male dispersal for an African colobine species. Previously, we have shown that female dispersal occurs in C. vellerosus (Teichroeb et al., 2009), which leaves open the possibility that males could remain in their natal group or emigrate. Here we examine the process of male emigration and the relationship between dispersal, BGEs, and male incursions. We ask the question, does the form and function of male incursions vary with male life-stage and/or temporal proximity to emigration? We also explore the frequency and ways that males moved between groups, the age class of emigrants and immigrants, the factors leading to emigration, the frequency of parallel emigration and immigration, and the outcome of immigration. Finally, we investigate which hypothesis for male dispersal is best supported for C. vellerosus at Boabeng-Fiema. 


\section{Methods}

\subsection{Study site and species}

This research was conducted at the Boabeng-Fiema Monkey Sanctuary (BFMS) in central Ghana $\left(7^{\circ} 43^{\prime} \mathrm{N}\right.$ and $\left.1^{\circ} 42^{\prime} \mathrm{W}\right)$, a dry semi-deciduous forest, 192 ha in size and located at an elevation of $350 \mathrm{~m}$ in the Nkoranza district of the Brong-Ahafo Region. BFMS is surrounded by farmland but connects to several smaller forest fragments in the area by a narrow, riparian forest. The vegetation is a mosaic of primary forest, regenerating farmland (secondary forest), and woodland (Fargey, 1991; Saj et al., 2005). Nineteen groups of $C$. vellerosus occupy the Boabeng-Fiema forest fragment, and five of the surrounding fragments (located within a $10 \mathrm{~km}$ radius) also present dispersal options as they contain 10 groups of colobus (Figure 1; Kankam et al., 2010).

At BFMS, C. vellerosus have been studied under the supervision of P.S. since 2000. They are mainly folivorous (annual diet: $74 \%$ leaves, Saj et al., 2005). Groups are multi-male/multi-female, uni-male/multi-female, or allmale bands (AMBs) (Saj et al., 2005). There is no mating or birth season (Teichroeb \& Sicotte, 2008b), and females show no external signs of ovulation. Between-group encounters (BGEs) are usually aggressive, with adult males as the main participants, but a small percentage of encounters involve no aggression (17\%, Sicotte \& MacIntosh, 2004). Group males, solitary males, and males in AMBs also attack and interact with bisexual groups during male incursions (Sicotte \& MacIntosh, 2004). Targeted aggression towards infants occurs during both BGEs and male incursions (Sicotte \& MacIntosh, 2004; Saj \& Sicotte, 2005). Several infanticides have been observed in this population after new males immigrated, and infanticide accounts for 38.5\% of infant mortality (Teichroeb \& Sicotte, 2008a). Putative sires may aid females in infant defence, if incoming males do not force them to emigrate (Saj \& Sicotte, 2005; Teichroeb \& Sicotte, 2008a,b).

\subsection{Study groups and data collection}

We used data from our seven research groups (B2, OD, DA, NP, RT, SP and WW). Groups were followed for varying amounts of time and were only included in this analysis if all adult and subadult males could be recognized (Table 1). Emigrations by juvenile males may be underestimated for two 


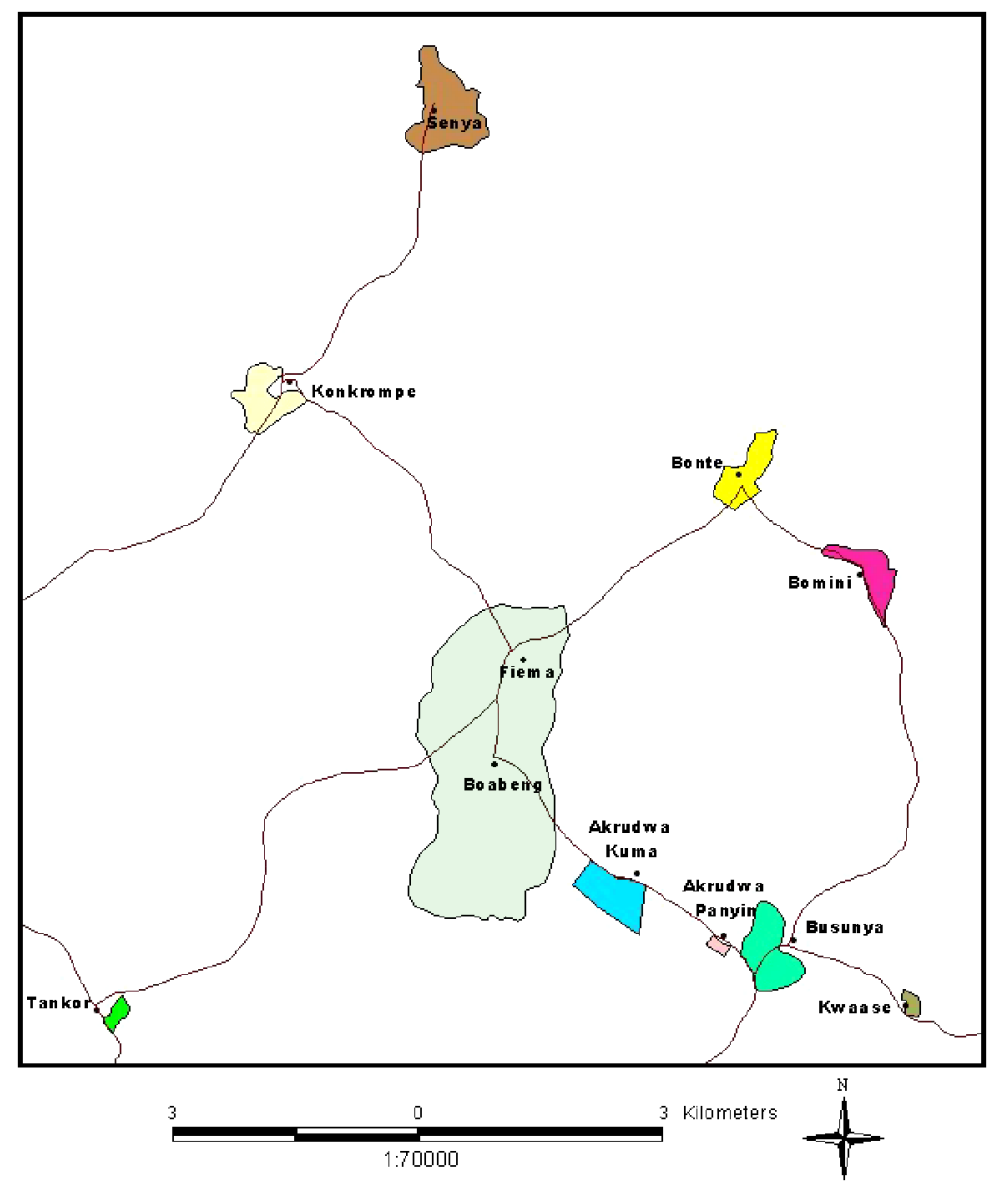

Figure 1. Map of Boabeng-Fiema and surrounding fragments (provided courtesy of Bright Kankam and Woeli Publishers, Accra, Ghana). Ursine colobus populations also exist in Akrukwa Kuma, Busunya, Bonte, Konkrompe and Bomini (Kankam et al., 2010). This figure is published in colour in the online edition of this journal, which can be accessed via http://www.brill.nl/beh

larger groups (DA and WW) because juveniles were difficult to individually recognize. Group size varied for each group across study years (Table 1).

Each study group was followed for at least one day per month (range 1-17 days, mean 3.52 days/month, Table 1) during follows lasting 7-12 $\mathrm{h}$ when researchers were present at the site. Behavioural observations were done using 10-min focal samples (Altmann, 1974) that were alternated among adult and subadult males and females with no individual sampled more than once 
Table 1. Study periods and group size.

\begin{tabular}{lccccccc}
\hline Group & $\begin{array}{c}\text { Years of } \\
\text { study }^{\mathrm{a}}\end{array}$ & $\begin{array}{c}\text { Months } \\
\text { of study }\end{array}$ & $\begin{array}{c}\text { Mean No. days } \\
\text { followed per } \\
\text { month }\end{array}$ & $\begin{array}{c}\text { Number } \\
\text { of follow } \\
\text { days }\end{array}$ & $\begin{array}{c}\text { Group } \\
\text { size range }\end{array}$ & $\begin{array}{c}\text { Number of } \\
\text { adult } \sigma^{7} \sigma^{7}\end{array}$ & $\begin{array}{c}\text { Number of } \\
\text { adult }+9\end{array}$ \\
\hline B2 & $2000-2010$ & 47 & 6 & $280^{\mathrm{b}}$ & $7-17$ & $1-7$ & $2-6$ \\
SP & $2006-2010$ & 13 & 2.2 & 29 & $9-17$ & 1 & $3-4$ \\
RT & $2003-2010$ & 32 & 3.9 & 124 & $8-27$ & $1-3$ & $5-7$ \\
OD & $2006-2010$ & 9 & 3 & 26 & $15-20$ & $1-6$ & $5-8$ \\
DA $^{\text {c }}$ & $2004-2010^{c}$ & 31 & 3.4 & 106 & $17-26$ & $3-8$ & $6-9$ \\
NP $^{c}$ & $2007-2010$ & 11 & 2.5 & 27 & $7-13$ & 1 & $4-6$ \\
WW & $2004-2010$ & 27 & 3.7 & 101 & $23-33$ & $2-10$ & $7-11$ \\
Total & & 170 & & 693 & & & \\
\hline
\end{tabular}

${ }^{a}$ Years of study with good individual identification so that dispersal events could be recorded.

b Including follows by J.A.T., E.C.W., T. Saj, A. MacIntosh, S. Marteinson and L. Brent.

${ }^{c}$ Between 2006 and 2007 NP group formed from DA individuals (Teichroeb et al., 2009).

per hour. Focal data presented here were collected in 2004-2005 by J.A.T. on four groups, RT, B2, DA and WW (202 follow days, 433.3 focal hours). Emigration and immigration events were recorded using all occurrences data collection, while copulations or male-male aggression occurring outside of focal samples were recorded ad libitum (Altmann, 1974). Group counts were usually obtained at least once per month.

\subsection{Definitions}

The age of dispersing and immigrating individuals was sometimes known but in most cases was estimated from the size of the individual relative to those of known age. Juvenile males (1-2 years old) were weaned and smaller than young subadult males, young subadult males (3-5 years old) were smaller than adult parous females, older subadult males (5-6 years old) were the same size as adult parous females, and adult males ( $\geqslant 7$ years old) had achieved full body size (larger than adult females) and regularly participated in loud call bouts with other adult males.

Rates of male emigration/disappearance and immigration were reported as number per male per year. We provided both the observed and inferred number of emigrations when we presented rates of emigration because this may provide a more accurate estimate of the number of males leaving groups. 
Observed cases were those where the researcher saw the process of emigration or a male from one group was seen residing in another group $(N=24)$. The inferred number includes those individuals that disappeared from the study groups $(N=48)$ when no observers were present and there was no evidence of death. No predators remain at BFMS that could take a subadult to adult sized colobus monkey and colobus hunting is rare, if it occurs at all (Saj et al., 2005). Adult male mortality caused by intra-specific aggression has been observed infrequently. Only three males have been observed to die from wounds they received in contests with other males (for one such case, see Sicotte et al., 2007). It, thus, seems unlikely that most disappearances are related to death because in all cases, individuals were young and/or appeared in good health, or emigrated involuntarily (see definition below). Thus, we included inferred cases when calculating rates of emigrations, but use only emigrations that were directly observed in all other analyses because the inclusion of disappearances as emigrations could lead to an overestimate of cases.

Natal emigration was defined as instances of departure from the group of birth. Natal emigration could only be determined where a male's group of birth was known. Secondary emigration was defined as males leaving a group into which they were known to have previously immigrated. Voluntary emigration was defined as individuals leaving a group without any observed increase in agonism towards them. Involuntary emigration was defined as emigration following increased aggression (e.g., threats, chasing, contact aggression) between males within a group during the previous days or weeks, observed during focal samples or ad libitum data collection. Depending on the males, aggression could be intense with the losing male(s) emigrating within a few days of its beginning or aggression could be prolonged in the weeks prior to emigration. Takeover events occurred when all the resident males emigrated within a few months of new male(s) immigrating. Betweengroup encounters (BGEs) occurred when individuals of both sexes from two groups came within $50 \mathrm{~m}$ of one another (Oates, 1977), while 'male incursions' occurred when males left their group and approached within $50 \mathrm{~m}$ of another group (Sicotte \& MacIntosh, 2004). At a distance of $50 \mathrm{~m}$ the groups could invariably see one another. Males were defined as forming a separate AMB phase when they left their group of origin and began to sleep and range with other males. 
Male dominance relationships were determined from the direction of aggression, displacements, avoidance, and submissive behaviours during focal samples and ad libitum observations. For this analysis, only male dominance interactions from stable periods, without challenges between males, were used. The direction of aggression and submission in each dyad did not differ between focal and ad libitum data. Male dominance relationships within each group were linear and males could be assigned a numerical rank. Bidirectionality in aggression was rare, occurring only in WW group when putative sires defended infants from new males (Teichroeb \& Sicotte, 2010). We defined 'high-intensity aggression' as instances with chases or contact aggression between subjects. Low-intensity aggression included threatening gestures such as stiff-legs, open-mouths and jump-displays (sensu Oates, 1977).

\subsection{Data analyses}

We present the mean duration of incursions for alpha versus non-alpha males. A mean duration per male was calculated and then used to compute an overall mean for duration, so that no single male with unusual durations skewed the results. Mann-Whitney $U$-tests were employed to examine differences in incursion duration and the proportion of incursions where the male initiated high-intensity aggression between alpha and non-alpha males, as well as to investigate rates of aggression received by immigrant adult males versus subadult males. Fisher's exact tests were used to establish: (1) whether males that emigrated voluntarily performed more incursions before emigrating compared to males that emigrated involuntarily; (2) the association between male age (adult or subadult) and the context surrounding emigration; (3) the relationship between male age and tendency to challenge dominants and become high-ranking in the new group; and (4) whether males that immigrated with others were more likely to challenge dominants than those that immigrated alone. Wilcoxon signed-rank tests were used to compare a male's rank before and after transferring to a new group, the sex ratios of original groups (including transferring males) with new groups (not including transferring males), and the percentage of males ranking higher than transferring males in new groups versus original groups. When examining the number of males in the new and original groups, transferring males were included in both counts. The duration of male tenure in a group was sometimes known exactly because the entrance (birth or immigration) of that male and the exit 
(death or emigration) were both observed. Whenever the entrance or the exit of a male was not observed, the duration of his tenure was truncated. Truncated tenure durations occurred either because the male was still in the group at the end of our data collection period, or the male entered and/or exited when observers were not present at the site. Since it is difficult to estimate the effect that truncated observations will have on tenure durations, we provide mean male tenure for both truncated and non-truncated observations. Tests were two-tailed and significance was set at $p \leqslant 0.05$. SPSS 16.0 was used for all tests except Fisher's exact tests, which were done using Preacher \& Briggs (2001) interactive calculation tool.

\section{Results}

\subsection{Male movement between groups}

Overall, 693 follow days were conducted for the seven study groups over differing numbers of study years (Table 1). Seventy-two male emigrations (24 observed, 48 inferred, $N=65$ males) and 62 male immigrations $(N=$ 55 males) occurred in the seven groups during the study periods. Forty-two males in the sample were involved in both emigration and immigration. In comparison, during the same time period in the same groups, 25 female emigrations (5 observed, 20 inferred, $N=25$ females) and four female immigrations ( $N=4$ females) occurred.

\subsection{Assessment of other groups during between-group encounters and male incursions}

Males could have assessed other groups for dispersal opportunities whenever groups met (e.g., aggressive and non-aggressive BGEs and male incursions). However, non-aggressive BGEs and incursions may allow males to gather more information about individuals from other groups through mingling and affiliative interactions. We, thus, analyzed non-aggressive BGEs and incursions separately. In this sample, $12.4 \%$ of all encounters were not aggressive $(71 / 572,14.2 \%$ of BGEs $(63 / 444)$ and $6.3 \%$ of male incursions $(8 / 128)$ ). More specifically, non-aggressive interactions involving individual males were recorded during 3.8\% of BGEs (17/444). In eleven of these interactions $(11 / 17,65 \%)$, males engaged in sexual behaviours such as presents, 
mounts, and copulations with females in the other group; playing $(2 / 17$, $11.8 \%)$, grooming $(2 / 17,11.8 \%)$, and touching were also observed $(2 / 17$, $11.8 \%)$. During incursions, non-alpha intruders sometimes mingled with individuals from the other group $(21.7 \%, 10 / 46)$ while alpha male intruders never did so $(0 / 26)$. Six non-aggressive interactions between intruding males and resident individuals were recorded during incursions $(4 / 46$ or $8.7 \%$ of incursions by non-alpha males). Half of these were sexual behaviour with females $50 \%$ (3/6), $33.3 \%$ was grooming (2/6), and $16.7 \%$ was playing (1/6). We also observed males residing in different groups present to one another during three BGEs and one male incursion.

Male incursions $(N=128)$ varied in duration and aggression level depending on the intruder's status. Incursions by non-alpha males were characterized by a slow and calm approach, which often involved males simply moving close to and watching the other group (28.9\% (13/45) compared to $7.1 \%(2 / 28)$ for alpha incursions). Incursions by alpha males were short (mean $=17.3 \mathrm{~min} ., \mathrm{SD}=11.0, N=8$ males) compared to non-alpha males (mean $=109.4$ min., $\mathrm{SD}=180.5, N=16$ males) $\left(N_{\text {alpha }}=8\right.$, $\left.N_{\text {non-alpha }}=16, Z=-2.05, p=0.04\right)$. We observed high-level aggression in most incursions by alpha males $(88.9 \%, 24 / 27$ incursions) and this aggression was initiated by the intruding alpha male in $77.3 \%$ of cases (17/22). Although $63.6 \%$ (28/44) of incursions initiated by non-alpha males also showed high-level aggression, the non-alpha intruder(s) initiated the aggression in only $31.6 \%(6 / 19)$ of incursions (when it could be determined who initiated aggression). Alpha male intruders initiated high-level aggression during a greater proportion of incursions compared to non-alpha male intruders $\left(N_{\text {alpha }}=8, N_{\text {non-alpha }}=12, Z=2.01, p=0.04\right)$. Indeed, since non-alpha male intruders did not always create agitation in the group, the frequency of incursions by non-alpha males may be underestimated.

In cases of voluntary emigration where a male's destination group was known ( $N=10$ males), $78.2 \%$ of the observed male incursions $(18 / 23)$ prior to immigration were directed towards the group the male transferred to (Table 2). There was a trend for males that emigrated voluntarily to show an increased frequency of incursions two months before leaving their group compared to males that emigrated involuntarily (6/11 voluntary dispersers versus $1 / 10$ involuntarily dispersers, Fisher's exact test: $p=0.06$ ). 


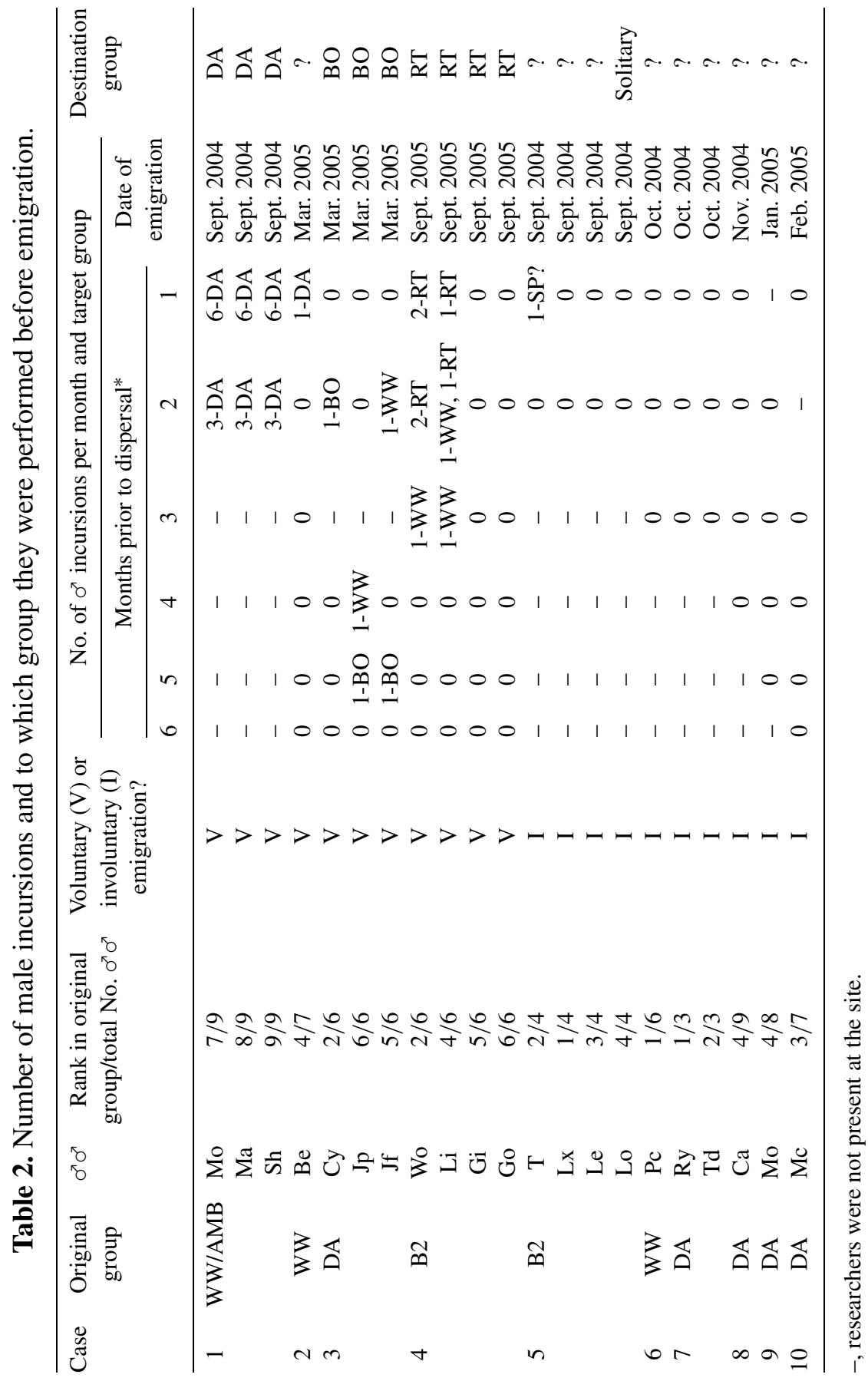




\subsection{Process of male emigration}

Adult males and subadult males showed similar rates of emigration/disappearance. Each year a mean of $31.4 \%$ of all adult males studied emigrated/disappeared (rate $0.04, N=10$ years, range $0-71.4 \%$ ), while $33.4 \%$ of subadult males emigrated/disappeared (rate $0.04, N=8$ years, range 0 $100 \%)$. The rate of juvenile male emigration/disappearance was 0.002 and the mean percentage of juvenile males that emigrated was $4.2 \%(N=8$ years, range: $0-33.3 \%$ ). In 63 cases of male emigration/disappearance, it was possible to discern whether males were natal or immigrants. Natal emigration/disappearance was made up of adult males $(7.3 \%, 3 / 41)$, subadult males $(80 \%, 16 / 20)$, and juvenile males $(50 \%, 1 / 2)$. Natal males emigrated at an estimated mean age of five years ( $N=18$, range: $2.5-7.5$ years $)$ and no males remained in their natal group after eight years of age.

Using only directly observed cases of emigration, the above results are similar, though rates of emigration were lower (adult males 0.008 , range $0-31.8 \%$, subadult males 0.017 , range $0-60 \%$, juvenile males 0 ) and all natal emigrations were by subadult males $(N=7)$. The following analyses include only directly observed cases of emigration.

Emigration was involuntary in $52.6 \%$ of cases (10/19) and voluntary in $47.4 \%$ of cases (9/19). Eight of 10 cases of involuntary emigration (80\%) involved adult males and six of nine cases of voluntary emigration involved subadult males (66.7\%). However, this distribution was not significantly skewed (Fisher's exact test, $p=0.07$ ). Alpha males always left involuntarily $(N=3)$ while only $43.8 \%$ of non-alpha adult males $(7 / 16)$ emigrated involuntarily. Aggression towards adult males before involuntary emigration was by new males in $70 \%$ of cases $(7 / 10)$ and by resident males in $30 \%$ of cases $(3 / 10)$.

Males emigrated singly and showed parallel emigration in $35.3 \%$ and $64.7 \%$ of cases, respectively $(N=17)$. For these cases of parallel emigration (three transfers of groups of three to four males), males were observed leaving their groups together and were later seen together in another group, with and without an AMB phase ( $N=11$ males). Observed natal male emigration was parallel in all cases $(N=7)$. It follows then that observed instances of parallel emigration involved mostly subadult males $(72.7 \%, 8 / 11)$. Males emigrated with members of their age-cohort and with males that had entered the group previously, in a wide age range (young subadults to adults). In one 
case, two transferring males in 2006 were known to be maternal half-siblings and possibly full-siblings that stayed together in their new group until 2008. In another case, a father-son dyad (E.C.W., unpubl. genetic data) transferred together in 2008 from OD to DA and remained until the end of the study in 2010.

In eight emigration events, the fate of 17 emigrating males was known. For these males, $70.6 \%(12 / 17$, Figure 2) transferred to a group with a more favourable AM/AF sex ratio than the one they left, that is, to a group with more adult females to adult males. When independent cases (i.e., taking into account the occurrence of parallel immigration) are compared, this was not significant $(N=8, Z=-1.68, p=0.093$; Figure 2). For nine transferring males, rank was known for both the original group and the new group. Three months after entering a new group, all immigrating males had improved their rank, compared to their rank in their original group, by forcing the emigration of resident males and males with whom they transferred $(N=9$,

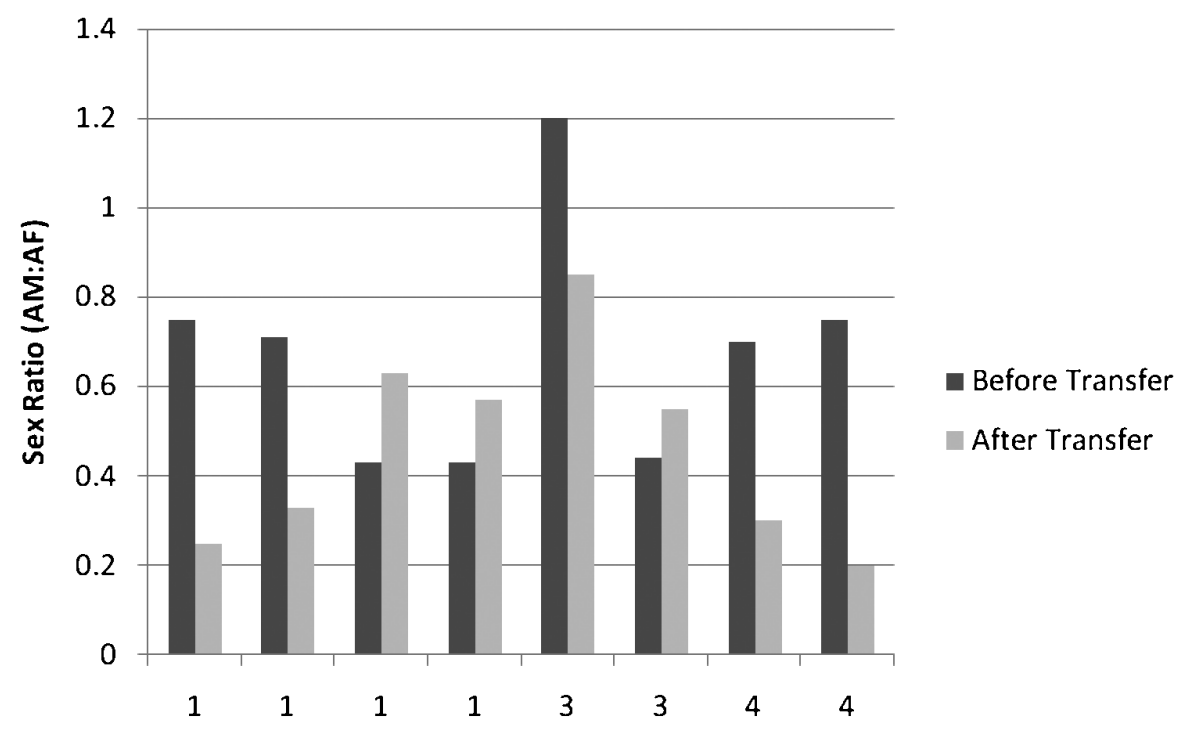

Total Number of Males in Transfer

Figure 2. The AM/AF ratio in the original group and the new group for transferring males in eight cases, some involving multiple males. In five of the eight cases, the males transferred into a group with more adult females to adult males than their original group. When cases with parallel transferring males are treated independently, the tendency to move towards groups containing more adult females to adult males than the original group was not significant $(N=8, Z=-1.68, p=0.093)$. 


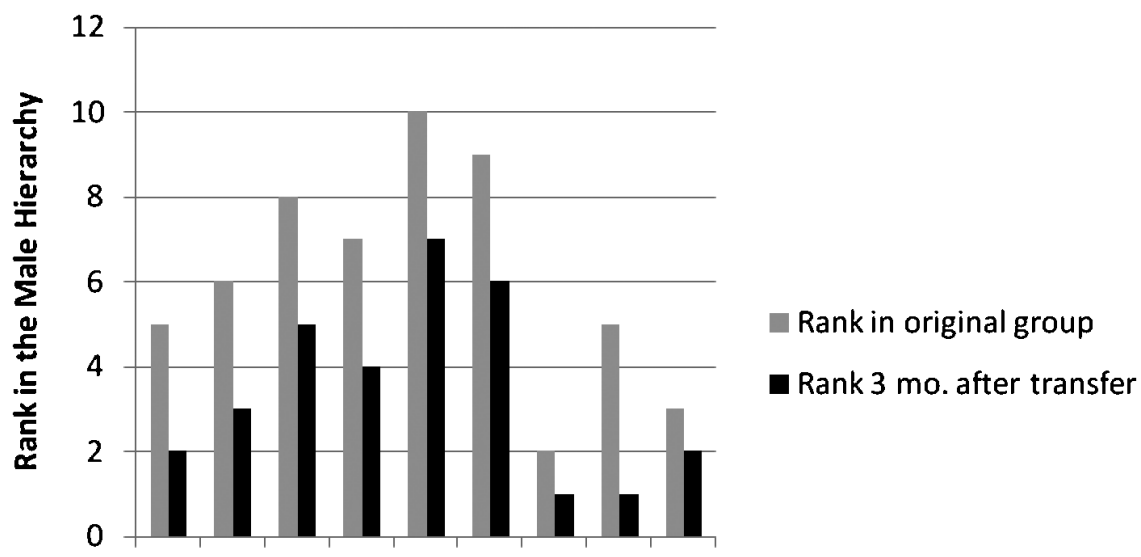

Gi Go Ma Mo Sc Sh Wo Tu Jd

Male

Figure 3. Dispersing males' rank in their original group compared to their new group, three months after transferring. All males improved their rank by transferring $(N=9$, $Z=-2.754, p=0.006$ ). All represented males transferred voluntarily, except $\mathrm{Tu}$ and Jd for whom data are not available.

$Z=-2.754, p=0.006$; Figure 3 ). This improvement in rank was largely a function of there being fewer males in the new group compared to the original group. All transferring males resided with a smaller percentage of males ranking higher than themselves three months after transfer, compared to the original group $(N=9, Z=2.78, p=0.005)$.

\subsection{Outcome of male immigration}

Immigration by adult males $(69.4 \%$ of cases $(43 / 62)$, rate 0.03$)$ was more common than by subadults $(29.0 \%$ of cases $(18 / 62)$, rate 0.03$)$ and juveniles $(1.6 \%$ (1/62), rate 0.002$)$. Male immigrations had a range of outcomes. Most often, a resident male(s) remained in the group and new males either challenged residents and became high-ranking (15/47 cases), or did not challenge and stayed low-ranking (15/47) (Table 3). Slow takeovers after male immigration(s) also occurred frequently (14/47) whereby all the resident male(s) emigrated within several months, involuntarily or voluntarily. However, when examining the participation of a single male in a slow takeover, he could (1) challenge dominants and become high-ranking, and be actively involved in the aggression directed at resident male(s), leading to their involuntary emigration (6/47); or (2) be one of several males immigrating into 
Table 3. Occurrence of different outcomes for male immigrations.

\begin{tabular}{lccccc}
\hline Outcome $(N=47)$ & $\begin{array}{c}\text { No. of } \\
\text { cases }\end{array}$ & $\begin{array}{c}\text { Occurrence } \\
(\%)\end{array}$ & $\begin{array}{c}\text { Adults } \\
(\%)\end{array}$ & $\begin{array}{c}\text { Subadults/ } \\
\text { juveniles } \\
(\%)\end{array}$ & $\begin{array}{c}\text { Parallel } \\
\text { immigration } \\
(\%)\end{array}$ \\
\hline $\begin{array}{l}\text { 1. Immediate takeover } \\
\begin{array}{l}\text { 2. Slow takeover: residents } \\
\text { gradually emigrate, }\end{array}\end{array}$ & 3 & 6.4 & 66.7 & $33.3^{*}$ & 66.7 \\
$\quad \begin{array}{l}\text { immigrant challenges and } \\
\text { becomes high-ranking }\end{array}$ & & 12.8 & 50 & 50 & 100 \\
$\begin{array}{l}\text { 3. Slow takeover: residents } \\
\text { gradually emigrate, }\end{array}$ & 8 & 17 & 62.5 & 37.5 & 100 \\
$\begin{array}{l}\text { immigrant does not challenge } \\
\text { and stays low-ranking, another } \\
\text { immigrant male becomes alpha }\end{array}$ & 15 & 31.9 & 100 & 0 & 33.3 \\
$\begin{array}{l}\text { 4. Resident male(s) stay but } \\
\text { immigrant challenges (becomes } \\
\text { high-ranking) }\end{array}$ & & & & & \\
$\begin{array}{l}\text { 5. Resident male(s) stay and } \\
\text { immigrant does not challenge } \\
\text { (stays low-ranking) }\end{array}$ & 15 & 31.9 & 46.1 & 53.8 & 71.4 \\
\hline
\end{tabular}

* Represents one older subadult male who was with an adult male that took-over a group.

the group, leading to a takeover, but not challenge dominants and stay lowranking (8/47). Quick takeovers, where all resident male(s) emigrated within a few days, were infrequent (3/47) (Table 3 ). A significantly greater proportion of adult males than subadults challenged dominants and became high ranking after immigration (Fisher's exact test: $p=0.05$ ) (Table 3). When the outcome was known $(N=40)$, young subadult males $(N=4)$ never challenged dominants, while $57.1 \%$ of the older subadult males (4/7) and $82.8 \%$ of adult males $(24 / 29)$ challenged dominants.

For 41 males it was possible to discern whether they had entered groups alone or with other males. Parallel immigration was more frequent $(70.7 \%$ of males $(29 / 41))$ than males entering groups alone (29.3\% of males $(12 / 41))$. The entire process of immigration was observed for five of 12 males that entered groups alone. In two of these five cases, the single male was aided in his initial attacks on the group by male(s) that disappeared before he immigrated. Parallel immigration was more frequent for adult males $(62.1 \%$ of cases, $18 / 29)$ than parallel emigration $(27.3 \%$ of cases, $3 / 11)$ suggesting that males gathered allies while between groups, potentially during an AMB 
phase. The opposite pattern was seen for subadult males who left groups in the company of others $72.7 \%$ of the time (8/11) but entered a new group with other males in only $34.5 \%$ of cases (10/29). There was no relationship between the tendency to challenge dominants and whether a male had entered the group alone or with others (Fisher's exact test: $p=0.39$ ) (Table 3).

\subsection{Resident male reactions to male immigration}

Resident males resisted male immigration in all but one of the observed cases ( $N=21$ immigrations), and the frequency and intensity of aggression that a male received upon entering a group was dependent upon his age. In the first three months after immigration, juveniles and young subadult males received little aggression (none recorded in focal-samples), while older subadult males received more (low and high-intensity aggression combined: mean $=0.017 / \mathrm{min}$ ), and adult males received the most (low and high-intensity aggression: mean $=0.044 / \mathrm{min})$. This difference in aggression received between adult and subadult males was significant $\left(N_{\text {Adults }}=6\right.$, $N_{\text {Subadults }}=5, Z=2.28, p=0.02$ ).

Of the 62 instances of male immigration in this study, at least 24 were into multi-male groups. The events surrounding these immigrations were well documented in 16 cases. When the interacting males could be recognized, chases and fights with the new male(s) were by single resident males in $88 \%$ of cases ( 15 of 17 encounters) and by coalitions of two resident males in 12\% of cases $(2 / 17)$. The alpha male was not always the primary aggressor. In WW group in 2004-2005, the 1st to 4th ranking adult males (out of 7 adult males) directed aggression at new males and the primary aggressor would often change during the days following a male immigration. In DA group, threats (stiff-legs and jump displays) between resident males and immigrants occurred at a rate of $0.45 / \mathrm{h}$ in the first three months after new males entered the group ( $N=9$ males) compared to $0.04 / \mathrm{h}$ in the absence of new males. The rate of high-intensity aggression also increased from $0.05 / \mathrm{h}$ to $0.11 / \mathrm{h}$. In all groups (having roughly the same number of males), we observed more fresh wounds among males in the first three months after a male immigration (0.29/month), compared to times with no male immigration $(0.12 /$ month).

\subsection{Male tenure}

Observations of male tenure were often truncated either because observers were not present during the month when the male immigrated or emigrated 
( $N=40)$ or because the male(s) were still present in the study groups $(N=9)$. Mean male tenure in groups, including truncated observations, was 18.9 months $(N=57$, range $1->71$ months, $\mathrm{SD}=19.1)$. When only male tenures that were completely observed are included, the mean was 22.3 months $(N=8$, range $1-58$ months, $\mathrm{SD}=25.1)$.

\section{Discussion}

\subsection{Rank and age effects on male dispersal patterns}

For Colobus vellerosus at BFMS, dispersal was male-biased although female dispersal also occurred (Teichroeb et al., 2009). Indeed, all males eventually left their natal group, while some females remained in their natal groups to breed (Teichroeb et al., 2009). Males transferred between groups frequently and appeared to assess other groups during BGEs and incursions before emigrating. Males often performed incursions towards a group before transferring into that group. Subadult males had more options for examining other groups and received less aggression upon entering groups than did adult males. Indeed, the function of male incursions in C. vellerosus appeared to vary depending on the life-stage and situation of the male(s). Incursions by non-alpha males seemed to be important in dispersal decisions. These males often approached other groups slowly, sometimes mingling with them. High-intensity aggression during incursions was usually initiated by the resident males towards the non-alpha male intruders. Younger, non-alpha males sometimes played with young individuals in the group and copulated with females during incursions. For several males, incursions increased in frequency before voluntary emigration, while this increase was not seen for males that emigrated involuntarily. These types of incursions allow nonalpha males to gauge the resistance they could encounter by immigrating to specific groups as well as the number of reproductively active females these groups include. Incursions to assess neighbours for dispersal or breeding opportunities have also been seen in many other animal species (e.g., mammals: Otaria byronia, Campagna et al., 1988; Suricata suricatta, Doolan \& Macdonald, 1996; Young et al., 2007; Colobus polykomos, Korstjens et al., 2005; birds: reviewed in Westneat \& Stewart, 2003).

Incursions by alpha males showed a different pattern. Alpha males often left their group to briefly and aggressively attack neighbouring groups, 
chasing resident males and sometimes females and infants (Sicotte \& MacIntosh, 2004), though a successful between-group infanticide has never been observed (Teichroeb \& Sicotte, 2008a). Incursions by alpha males are consistent with the idea that these interactions work to convey information about the quality of the male, which has also been reported in mountain gorillas (Gorilla beringei beringei, Watts, 1994) and Thomas langurs (Presbytis thomasi, Steenbeek, 1999). Alpha males appear to be displaying their strength, testing the competitiveness of resident male(s), and perhaps trying to entice females to transfer to their group (Watts, 1994; Steenbeek, 1999). Indeed, in some species, males of greater quality perform more and suffer fewer incursions (e.g., mammals: P. thomasi, Steenbeek, 1999; birds: Luscinia megarhychos, Naguib et al., 2001; Geothlypis trichas, Pedersen et al., 2006). These encounters must necessarily be brief however, as alpha males could lose the females in their own group and put their own infants in danger if they are gone long from their group.

Rank was also an important determinant of the way in which males emigrated. Alpha males always emigrated involuntarily. Being alpha and being able to mate guard females (Teichroeb \& Sicotte, 2010) gives males many reproductive opportunities and, thus, alpha males resisted leaving their group. Whether or not males have (or perceived that they have) sired infants in their group, may also affect whether alpha males stayed in their group after being deposed. When new males were successful in taking over a group, but not able to force the resident males to emigrate, former high ranking males often stayed in their resident group (e.g., Theropithecus gelada, Dunbar, 1984). These formerly high-ranked males frequently defended infants against intruding male(s) (Saj \& Sicotte, 2005; Teichroeb \& Sicotte, 2008a), although paternity is currently unknown. In Hanuman langurs (Semnopithecus entellus) at Ramnagar, Borries et al. (1999) found that males that were alpha when infants were sired stayed to defend those infants after new male(s) immigrated. These males defended their genetic offspring exclusively. Males that had not been present in the group during the previous mating season did not remain in the group.

Parallel emigration and immigration were frequent for C. vellerosus males. As with most primate species in which it has been reported (reviewed in Pusey \& Packer, 1987a; Schoof et al., 2009), parallel emigration was more common for subadult males than for adult males. However, adult male $C$. vellerosus showed higher levels of parallel immigration than did subadult 
males. This indicates that adult males were joining other males while between groups and that the benefits of entering groups with allies must be substantial for adult males, who receive more aggression upon entering new groups than do subadult males. Maintaining allies between transfers and creating new coalitions before immigrating probably gives males better odds of successfully entering and/or taking over a group (Pusey \& Packer, 1987a; Schoof et al., 2009). Since subadult males received less aggression after entering groups compared to adult males, they may not need allies to the same extent in that context. When the process of joining other males takes time, a distinct AMB phase may be seen by researchers. For $C$. vellerosus however, AMBs do not appear to last very long or be very stable in comparison with some other primate species (e.g., S. entellus, Hrdy, 1977; T. gelada, Dunbar, 1984) because full-count censuses performed intensively for a few weeks every few years at BFMS have yet to report AMBs (Saj et al., 2005; Wong $\&$ Sicotte, 2006; Kankam et al., 2010). When AMBs have been observed $(N=2)$, their composition was quite fluid. They selected a bisexual group to attack and integrate into within the first couple of months of their existence (J.A.T., unpubl. data).

Parallel dispersal for male $C$. vellerosus often occurred with members of their age-cohort, who may have been sired by the same male. Thus, these males may have been related up to the level of half-siblings and may have gained inclusive fitness benefits by aiding one another (van Hooff, 2000). It is still unknown whether $C$. vellerosus males can maintain alliances over several migrations as has been seen in squirrel monkeys (Saimiri sciureus, Mitchell, 1994) and white-faced capuchins (Cebus capucinus, Jack \& Fedigan, 2004b). Males that form coalitions in AMBs do not seem to maintain their alliances once they enter a new group and they often attempt to force one another to emigrate. Nonetheless, males that come from the same group do seem to form longer-term coalitions. Four males from the same age cohort in WW that transferred together to DA in 2004 did not direct aggression at one another and two of them were still together until 2009. In addition, the maternal brothers that transferred from B2 to RT in 2006 and the father/son dyad that transferred to DA in 2008 were not seen to direct aggression at one another and remained together for several years.

The outcome of male immigration at BFMS showed that males usually immigrated into a group and either stayed low-ranking or gained high-rank without the former resident males leaving. Slow takeovers, where all of the 
resident male(s) emigrated within a few months, also occurred frequently and were always accomplished by males that transferred in parallel (Table 3). Quick takeovers, where the resident male(s) was ousted within a few days, did not occur often. Immigrant males challenged dominant males and attempted to rise in rank more often when they were adult. Whether or not males challenge dominants probably depends on an assessment of their strength relative to other males and their odds of a rise in rank. Previous research has shown that male $C$. vellerosus use display behaviours to assess one another's strength (Teichroeb \& Sicotte, 2010) and new males who challenge dominants and rise in rank are also those most likely to attack infants (Teichroeb \& Sicotte, 2008a).

\subsection{Why do C. vellerosus males disperse?}

All natal male $C$. vellerosus at BFMS dispersed eventually and voluntarily. The mean age of natal emigration was five years, generally occurring before males were fully adult as estimated by their body size (approx. 7 years of age). Dispersing natal males avoid mating with natal females and older females who may be related to the male. However, the inbreeding avoidance hypothesis may not be the best explanation for natal male dispersal in this population. Males lose little by mating with a relative, while female fitness can be highly affected by the costs of inbreeding depression (Parker, 1979; Waser et al., 1986). Thus, females are expected to be choosy and avoid mating with related males. The number of available mates is, therefore, likely to be lower than overall female group size within a male's natal group, and males may disperse to find more mates (Lehmann \& Perrin, 2003). Natal males may also have increased their mating opportunities by dispersing since they gained higher dominance rank in their new group and tended to transfer to groups with a more beneficial sex ratio. Indeed, if C. vellerosus avoid breeding with their relatives, our analyses of adult male/adult female ratios in original versus new groups for transferring males would have more accurately reflected available mates if we had used adult male/unrelated adult female ratios. Nevertheless, genetic data is not yet available for this entire population. These results suggest that inbreeding avoidance might not be the main cause of natal dispersal and that the best ultimate explanation for male natal dispersal in this population is the intrasexual competition for mates hypothesis. However, since natal males always emigrated voluntarily, 
intrasexual competition between males may not fully explain natal dispersal; rather female mate choice may limit a natal male's access to mates and these males may disperse to increase reproductive opportunities.

Dispersal for inbreeding avoidance may sometimes apply to adult male C. vellerosus, who, in certain circumstances, may emigrate to avoid mating with their maturing daughters (Cheney, 1983; Pusey \& Packer, 1987a; Clutton-Brock, 1989). These situations seem rare, however. Females normally begin mating between 3 and 5 years of age in this species (J.A.T. \& E.C.W., unpubl. data) and relatively few males at BFMS have tenures approaching this length (range $>51->71$ months, $N=7 / 58$ males, or $12.1 \%$ ). Females also have the possibility of emigrating from their natal group if their father is still resident (Teichroeb et al., 2009) and approx. 77\% of groups at BFMS are multi-male (Saj et al., 2005). Therefore, daughters in all likelihood have the option of mating with males other than their father, even if he is resident.

The intrasexual competition for mates hypothesis is the best explanation for secondary male dispersal at BFMS. In the majority of cases (and in all cases for alpha males), emigration was involuntary and caused by aggression from other males. Adult males received a high level of aggression upon entering new groups. Involuntary emigrations were most commonly caused by new male immigration; thus, intrasexual competition appeared to be stronger from extra-group males than from intra-group males. When the fate of males was known, many moved towards groups with a more favourable adult male/adult female ratio than their original group. They also improved their rank by transferring because there were fewer males in the new group, which likely led to an increase in breeding opportunities. These results are congruent with most primate studies which have found that male transfer can be best explained by male reproductive competition (e.g., Packer, 1979; Packer \& Pusey, 1987a; Sussman, 1992; Alberts \& Altmann, 1995; Borries, 2000; Korstjens, 2001; Jack, 2003; Jack \& Fedigan, 2004a,b; Clarke et al., 2008). Several males in this study transferred at least three times and for most males, tenure was relatively short, indicating that $C$. vellerosus males continue to move between groups for their entire lives. This pattern has been seen in several primate species and in lions (reviewed in Jack, 2003) and is thought to be due to males continually trying to increase their reproductive success by voluntarily transferring between groups or trying to immigrate into another group after involuntary emigration. 


\subsection{Dispersal in a fragmented landscape}

In fragmented landscapes, research has shown that dispersal may be inhibited (e.g., amphibians: Gibbs, 1998; reptiles: Egernia cunninghami, Stow et al., 2001; marsupials: Lasiorhinus latifrons, Walker et al., 2008) or dispersal distances may be longer but a smaller proportion of animals will migrate (e.g., mammals: Diffendorfer et al., 1995; birds: Sitta europaea, Matthysen et al., 1995). Census data of BFMS and the surrounding fragments has demonstrated that though the colobus population in the Boabeng-Fiema fragment has increased over time, in both the number of individuals and groups, the population size of the smaller fragments has remained relatively similar since 1997 (Wong \& Sicotte, 2006), though some additional fragments have become populated (Kankam et al., 2010). This suggests that the BoabengFiema fragment probably acts as the source population and the smaller surrounding fragments are sinks. However, we cannot rule out that some individuals born in the smaller fragments may disperse to BFMS (Wong \& Sicotte, 2006), possibly due to a higher number of available mates or superior habitat quality. BFMS may consist of better habitat since it has a more complex forest structure (Kankam et al., 2010) and is less disturbed than the smaller fragments (Wong et al., 2006). Although colobus move between fragments, BFMS provides more dispersal opportunities since it contains 19 groups. Therefore, we think it is likely that the majority of the individuals in our study groups transferred to other groups in this fragment. When we knew the location of transferring males in this study, they had usually joined a neighbouring group; however this data is skewed because we did not monitor groups outside of the study area. The probability of identifying a dispersing male in a neighbouring group is, thus, higher than in a group located further away from the original group.

\subsection{What do the male dispersal patterns in C. vellerosus tell us about their group formation?}

Data from BFMS seem to indicate that group formation in C. vellerosus is often a function of parallel dispersal by several females (Teichroeb et al., 2009) who establish a home range and attract males. Female residency then appears to remain relatively stable (E.C.W., unpubl. data), while male residency is more fluid and changes more frequently. Solitary males or AMBs attracting females to them, a process which occurs in some primate species 
(e.g., Gorilla beringei beringei, Sicotte, 1993; Watts, 2000; Stoinski et al., 2009; Presbytis thomasi, Sterck, 1997; Trachypithecus phayrei, Koenig \& Borries, submitted) and in many bird species (Greenwood, 1980; Dobson, 1982) has never been observed in C. vellerosus. This lends support to the notion that male $C$. vellerosus are not responsible for establishing home ranges, though their behaviour in BGEs after a group is established can be compatible with resource defence (Sicotte \& MacIntosh, 2004), as has been shown for C. guereza (Fashing, 2001; Harris, 2010). Once groups are established, female $C$. vellerosus show longer tenures and greater allegiance than males to their group and their range (Teichroeb et al., 2009).

\section{Acknowledgements}

We would like to thank the Ghana Wildlife Division and the management committee of the Boabeng-Fiema Monkey for permission to conduct this research. Funding was provided by Alberta Ingenuity, American Society of Primatologists, International Primatological Society, L.S.B. Leakey Foundation, NSERC, Province of Alberta, Sweden-America Foundation, and the University of Calgary. Research assistance was provided by Lauren Brent, Rachel Boratto, Robert Koranteng, Kwame Duodo, Kwaku Amponsah, Johanna Hedlund, Danica Stark, Lucy Anderson, Fernando Campos, and Teresa Holmes. Contributions to the database on dispersals and immigrations at BFMS were provided by Tania Saj, Andrew MacIntosh, Sarah Marteinson and Lauren Brent. We would also like to thank Andreas Koenig and Josie Vayro who provided useful advice and three anonymous reviewers for helpful comments. Data collection methods complied with the rules of the University of Calgary's Animal Care Committee and with the laws of Ghana.

\section{References}

Agoramoorthy, G. \& Rudran, R. (1993). Male dispersal among free-ranging red howler monkeys (Alouatta seniculus) in Venezuela. - Folia Primatol. 61: 92-96.

Alberts, S.C. \& Altmann, J. (1995). Balancing costs and opportunities: dispersal in male baboons. - Am. Nat. 145: 279-306.

Altmann, J. (1974). Observational study of behaviour: sampling methods. — Behaviour 49: $227-267$.

Altmann, J. (1979). Age cohorts as paternal sibships. - Behav. Ecol. Sociobiol. 6: 161-164.

Altwegg, R., Ringsby, T.R. \& Saether, B.E. (2000). Phenotypic correlates and consequences of dispersal in a metapopulation of house sparrows Passer domesticus. - J. Anim. Ecol. 69: 762-770.

Arcese, P. (1989). Intrasexual competition, mating system and natal dispersal in song sparrows. - Anim. Behav. 38: 958-979.

Barbraud, C., Johnson, A.R. \& Bertault, G. (2003). Phenotypic correlates of post-fledging dispersal in a population of greater flamingos: the importance of body condition. - J. Anim. Ecol. 72: 246-257. 
Borries, C. (2000). Male dispersal and mating season influxes in Hanuman langurs living in multi-male groups. - In: Primate males (Kappeler, P.M., ed.). Cambridge University Press, Cambridge, p. 146-158.

Borries, C., Launhardt, K., Epplen, C., Epplen, J.T. \& Winkler, P. (1999). Males as infant protectors in hanuman langurs (Presbytis entellus) living in multi-male groups - defense pattern, paternity, and sexual behavior. - Behav. Ecol. Sociobiol. 46: 350-356.

Campagna, C., Le Boeuf, B.J. \& Cappozzo, H.L. (1988). Group raids: a mating strategy of male southern sea lions. - Behaviour 105: 224-249.

Cheney, D.L. (1983). Proximate and ultimate factors related to the distribution of male migration. - In: Primate social relationships (Hinde, R.A., ed.), Blackwell Scientific, Oxford, p. 241-249.

Cheney, D.L. \& Seyfarth, R.M. (1983). Nonrandom dispersal in free-ranging vervet monkeys: social and genetic consequences. - Am. Nat. 122: 392-412.

Clark, P.M.R., Henzi, S.P., Barrett, L. \& Rendall, D. (2008). On the road again: competitive effects and condition-dependent dispersal in male baboons. - Anim. Behav. 76: 55-63.

Clutton-Brock, T.H. (1989). Female transfer and inbreeding avoidance in social mammals. - Nature 337: 70-72.

Clutton-Brock, T.H. \& Sheldon, B.C. (2010). Individuals and populations: the role of longterm, individual-based studies of animals in ecology and evolutionary biology. Trends Ecol. Evol. 25: 562-575.

Diffendorfer, J.E., Gaines, M.S. \& Holt, R.D. (1995). Habitat fragmentation and movements of three small mammals (Sigmodon, Microtus, and Peromyscus). — Ecology 76: 827839.

Dobson, F.S. (1982). Competition for mates and predominant juvenile male dispersal in mammals. - Anim. Behav. 30: 1183-1192.

Doolan, S.P. \& Macdonald, D.W. (1996). Dispersal and extra-territorial prospecting by slender-tailed meerkats (Suricata suricatta) in the south-western Kalahari. - J. Zool. Lond. 240: 59-73.

Drickamer, L.C. \& Vessey, S.H. (1973). Group changing in free-ranging male rhesus monkeys. - Primates 14: 359-368.

Dunbar, R.I.M. (1984). Reproductive decisions. — Princeton University Press, Princeton, NJ.

Ekernas, L.F. \& Cords, M. (2007). Social and environmental factors influencing natal dispersal in blue monkeys, Cercopithecus mitis stuhlmanni. - Anim. Behav. 73: 1009-1020.

Fargey, P.J. (1991). Assessment of the conservation status of the Boabeng-Fiema Monkey Sanctuary. - Final report to the Flora and Fauna Preservation Society, University of Science and Technology, Kumasi.

Fashing, P.J. (2001). Male and female strategies during intergroup encounters in guerezas (Colobus guereza): evidence for resource defence mediated through males and a comparison with other primates. - Behav. Ecol. Sociobiol. 50: 219-230.

Gibbs, J.P. (1998). Amphibian movements in response to forest edges, roads, and streambeds in southern New England. - J. Wildl. Manage. 62: 584-589.

Gould, L. (2006). Male sociality and integration during the dispersal process in Lemur catta: a case study. - In: Ringtailed lemur biology: Lemur catta in Madagascar (Jolly, A., Koyama, N. \& Rasamimanana, H., eds). Springer Science and Business Media, New York, NY, p. 296-310.

Greenwood, P.J. (1980). Mating systems, philopatry and dispersal in birds and mammals. Anim. Behav. 28: 1140-1162. 
Griesser, M., Nystrand, M., Eggers, S. \& Ekman, J. (2008). Social constraints limit dispersal and settlement decisions in a group-living bird species. - Behav. Ecol. 19: 317-324.

Harris, T.R. (2010). Multiple resource values and fighting ability measures influence intergroup conflict in guerezas (Colobus guereza). - Anim. Behav. 79: 89-98.

Henzi, S.P. \& Lucas, J.W. (1980). Observations on the intertroop movement of adult vervet monkeys (Cercopithecus aethiops). - Folia Primatol. 33: 220-235.

Hrdy, S.B. (1977). The langurs of Abu. — Harvard University Press, Cambridge, MA.

Isbell, L.A. (2004). Is there no place like home? Ecological bases of female dispersal and philopatry and their consequences for the formation of kin groups. - In: Kinship and behavior in primates (Chapais, B. \& Berman, C.M., eds). Oxford University Press, New York, NY, p. 71-108.

Isbell, L.A. \& Van Vuren, D. (1996). Differential costs of locational and social dispersal and their consequences for female group-living primates. - Behaviour 133: 1-36.

Itani, J. (1972). A preliminary essay on the relationships between social organization and incest avoidance in nonhuman primates. — In: Primate socialization (Poirier, F.E., ed.). Random House, New York, NY, p. 165-171.

Jack, K.M. (2003). Males on the move: evolutionary explanations of secondary dispersal by male primates. - Primate Report 67: 61-83.

Jack, K.M. \& Fedigan, L.M. (2004a). Male dispersal patterns in white-faced capuchins, Cebus capucinus. Part 1: patterns and causes of natal emigration. - Anim. Behav. 67: 761-769.

Jack, K.M. \& Fedigan, L.M. (2004b). Male dispersal patterns in white-faced capuchins, Cebus capucinus. Part 2: patterns and causes of secondary dispersal. - Anim. Behav. 67: 771-782.

Johnson, M.L. \& Gaines, M.S. (1990). Evolution of dispersal: theoretical models and empirical tests using birds and mammals. - Annu. Rev. Ecol. Syst. 21: 449-480.

Kankam, B.O., Saj, T.L. \& Sicotte, P. (2010). How to measure "success" in community-based conservation projects: the case of the Boabeng-Fiema Monkey Sanctuary in Ghana. In: The public sphere and politics of survival in Ghana (Puplampu, K.P. \& Tettey, W.J., eds). Woeli Publishers, Accra, p. 115-141.

Korstjens, A.H. (2001). The mob, the secret sorority, and the phantoms: an analysis of the socio-ecological strategies of the three colobines of Taï. — PhD thesis, Utrecht University, Utrecht.

Korstjens, A.H., Nijssen, E.C. \& Noë, R. (2005). Intergroup relationships in western blackand-white colobus, Colobus polykomos polykomos. — Int. J. Primatol. 26: 1267-1289.

Krofel, M., Filacorda, S. \& Jerina, K. (2010). Mating-related movements of male brown bears on the periphery of an expanding population. - Ursus 21: 23-29.

Le Boeuf, B.J. \& Reiter, J. (1988). Lifetime reproductive success in northern elephant seals. - In: Reproductive success. Studies of individual variation in contrasting breeding systems (Clutton-Brock, T.H., ed.). Chicago University Press, Chicago, IL, p. 344-362.

Lehmann, L. \& Perrin, N. (2003). Inbreeding avoidance through kin recognition: choosy females boost male dispersal. - Am. Nat. 162: 638-652.

Macdonald, D.W., Newman, C., Buesching, C.D. \& Johnson, P.J. (2008). Male-biased movement in a high-density population of the Eurasian badger (Meles meles). — J. Mammal. 89: 1077-1086.

Matthysen, E., Andriaensen, F. \& Dhondt, A.A. (1995). Dispersal distances of nuthatches, Sitta europaea, in a highly fragmented forest habitat. — Oikos 72: 375-381. 
McCauley, S.J. (2010). Body size and social dominance influence breeding dispersal in male Pachydiplax longipennis (Odonata). - Ecol. Entomol. 35: 377-385.

McCoy, J.A., Hewitt, D.G. \& Bryant, F.C. (2005). Dispersal by yearling white-tailed deer and implications for management. — J. Wildl. Manage. 69: 366-376.

Meylan, S., Belliure, J., Clobert, J. \& de Fraipont, M. (2002). Stress and body condition as prenatal and postnatal determinants of dispersal in the common lizard (Lacerta vivipara). - Horm. Behav. 42: 319-326.

Mitchell, C.L. (1994). Migration alliances and coalitions among adult male South American squirrel monkeys (Saimiri sciureus). - Behaviour 130: 169-190.

Moore, J. \& Ali, R. (1984). Are dispersal and inbreeding avoidance related? - Anim. Behav. 32: 94-112.

Naguib, M., Altenkamp, R. \& Griessmann, B. (2001). Nightingales in space: song and extraterritorial forays of radio tagged song birds. - J. Ornithol. 142: 306-312.

Nutt, K.J. (2008). A comparison of techniques for assessing dispersal behaviour in gundis: revealing dispersal patterns in the absence of observed dispersal behaviour. - Mol. Ecol. 17: 3541-3556.

Oates, J.F. (1977). The social life of a black-and-white colobus monkey, Colobus guereza. Z. Tierpsychol. 45: 1-60.

Okamoto, K., Matsumura, S. \& Watanabe, K. (2000). Life history and demography of wild moor macaques (Macaca maurus): summary of ten years of observations. - Am. J. Primatol. 52: 1-12.

Packer, C. (1979). Intertroop transfer and inbreeding avoidance in Papio anubis. - Anim. Behav. 27: 1-36.

Parga, J.A. \& Lessnau, R.G. (2008). Dispersal among male ring-tailed lemurs (Lemur catta) on St. Catherines Island. — Am. J. Primatol. 70: 650-660.

Parker, G.A. (1979). Sexual selection and sexual conflict. — In: Sexual selection and reproductive competition in insects (Blum, M.S. \& Blum, N.A., eds). Academic Press, New York, NY, p. 123-166.

Pedersen, M.C., Dunn, P.O. \& Whittingham, L.A. (2006). Extraterritorial forays are related to a male ornamental trait in the common yellowthroat. - Anim. Behav. 72: 479-486.

Poirier, F.E. (1970). The nilgiri langur (Presbytis johnii) of south India. — In: Primate behaviour: developments in field and laboratory research (Rosenblum, L.A., ed.). Academic Press, New York, NY, p. 251-383.

Preacher, K.J. \& Briggs, N.E. (2001). Calculation for Fisher's exact test: an interactive calculation tool for Fisher's exact probability test for $2 \times 2$ tables [computer software]. Available online at http://www.quantpsy.org

Pusey, A.E. (1987). Sex-biased dispersal and inbreeding avoidance in birds and mammals. Trends Ecol. Evol. 2: 295-299.

Pusey, A.E. (1992). The primate perspective on dispersal. — In: Animal dispersal: small mammals as a model (Stenseth, N.C. \& Lidicker Jr., W.Z., eds). Chapman \& Hall, London, p. 243-259.

Pusey, A.E. \& Packer, C. (1987a). Dispersal and philopatry. — In: Primate societies (Smuts, B.B., Cheney, D.L., Seyfarth, R.M., Wrangham, R.W. \& Struhsaker, T.T., eds). University of Chicago Press, Chicago, IL, p. 250-266.

Pusey, A.E. \& Packer, C. (1987b). The evolution of sex-biased dispersal in lions. - Behaviour 101: 275-310. 
Saj, T.L. \& Sicotte, P. (2005). Male takeover in Colobus vellerosus at Boabeng-Fiema Monkey Sanctuary, central Ghana. - Primates 46: 211-214.

Saj, T.L., Teichroeb, J.A. \& Sicotte, P. (2005). The population status of the ursine colobus (Colobus vellerosus) at Boabeng-Fiema, Ghana. - In: Commensalism and conflict: the human primate interface (Paterson, J.D. \& Wallis, J., eds). American Society of Primatologists, Norman, OK, p. 350-375.

Schoof, V.A.M., Jack, K.M. \& Isbell, L.A. (2009). What traits promote male parallel dispersal in primates? - Behaviour 146: 701-726.

Shields, W.M. (1987). Dispersal and mating systems: investigating their causal connections. - In: Mammalian dispersal patterns: the effects of social structure on population genetics (Chepko-Sade, D. \& Halpin, Z.T., eds). University of Chicago Press, Chicago, IL, p. 3-24.

Sicotte, P. (1993). Inter-group encounters and female transfer in mountain gorillas: influence of group composition on male behavior. - Am. J. Primatol. 30: 21-36.

Sicotte, P. \& MacIntosh, A.J. (2004). Inter-group encounters and male incursions in Colobus vellerosus in central Ghana. - Behaviour 141: 533-553.

Sicotte, P., Teichroeb, J.A. \& Saj, T.L. (2007). Aspects of male competition in Colobus vellerosus: preliminary data on male and female loud calling, and infant deaths after a take-over. - Int. J. Primatol. 28: 627-636.

Smale, L., Nunes, S. \& Holekamp, K.E. (1997). Sexually dimorphic dispersal in mammals: patterns, causes, and consequences. - Adv. St. Behav. 26: 181-250.

Smith, E.O. (1992). Dispersal in sub-Saharan baboons. — Folia Primatol. 59: 177-185.

Steenbeek, R. (1999). Tenure related changes in wild Thomas langurs I: between-group encounters. - Behaviour 136: 595-625.

Sterck, E.H.M. (1997). Determinants of female dispersal in Thomas langurs. - Am. J. Primatol. 42: 179-198.

Stoinski, T.S., Vecellio, V., Ngaboyamahina, T., Ndagijimana, F., Rosenbaum, S. \& Fawcett, K.A. (2009). Proximate factors influencing dispersal decisions in male mountain gorillas, Gorilla beringei beringei. - Anim. Behav. 77: 1155-1164.

Stow, A.J., Sunnucks, P., Briscoe, D.A. \& Gardner, M.G. (2001). The impact of habitat fragmentation on dispersal of Cunningham's skink (Egernia cunninghami): evidence from allelic and genotypic analyses of microsatellites. - Mol. Ecol. 10: 867-878.

Sugiyama, Y. \& Ohsawa, H. (1975). Life history of male Japanese macaques at Ryozenyama. - In: Contemporary primatology: proceedings of the fifth congress of the International Primatological Society (Kondo, S., Kawai, M. \& Ehara, A., eds). Karger, Basel, p. 407410.

Sussman, R.W. (1992). Male life history and intergroup mobility among ring-tailed lemurs (Lemur catta). - Int. J. Primatol. 13: 395-413.

Teichroeb, J.A. \& Sicotte, P. (2008a). Infanticide in ursine colobus monkeys (Colobus vellerosus): new cases and a test of the existing hypotheses. - Behaviour 145: 727-755.

Teichroeb, J.A. \& Sicotte, P. (2008b). Social correlates of fecal testosterone in male ursine colobus monkeys (Colobus vellerosus): the effect of male reproductive competition in aseasonal breeders. - Horm. Behav. 54: 417-423.

Teichroeb, J.A. \& Sicotte, P. (2010). The function of male agonistic displays in ursine colobus monkeys (Colobus vellerosus): male competition, female mate choice or sexual coercion? - Ethology 116: 366-380. 
Teichroeb, J.A., Wikberg, E.C. \& Sicotte, P. (2009). Female dispersal patterns in six groups of ursine colobus (Colobus vellerosus): infanticide avoidance is important. - Behaviour 146: 551-582.

Trivers, R. (1972). Parental investment and sexual selection. - In: Sexual selection and the descent of man (Campbell, B., ed.). Aldine, Chicago, IL, p. 136-179.

van Hooff, J.A.R.A.M. (2000). Relationships among non-human primate males: a deductive framework. - In: Primate males (Kappeler, P.M., ed.). Cambridge University Press, Cambridge, p. 183-191.

van Noordwijk, M.A. \& van Schaik, C.P. (1985). Male migration and rank acquisition in wild long-tailed macaques (Macaca fascicularis). — Anim. Behav. 33: 849-861.

van Noordwijk, M.A. \& van Schaik, C.P. (2004). Sexual selection and the careers of primate males: paternity concentration, dominance-acquisition tactics and transfer decisions. In: Sexual selection in primates: new and comparative perspectives (Kappeler, P.M. \& van Schaik, C.P., eds). Cambridge University Press, Cambridge, p. 208-229.

van Schaik, C.P. (1989). The ecology of social relationships amongst female primates. In: Comparative socioecology: the behavioural ecology of humans and other mammals (Standen, V. \& Foley, R.A., eds). Blackwell Scientific, Oxford, p. 195-218.

Walker, F.M., Sunnucks, P. \& Taylor, A.C. (2008). Evidence for habitat fragmentation altering within-population processes in wombats. - Mol. Ecol. 17: 1674-184.

Waser, P.M., Austad, S.N. \& Keane, B. (1986). When should animals tolerate inbreeding? Am. Nat. 128: 529-537.

Watts, D. (1994). The influence of male mating tactics on habitat use in mountain gorillas (Gorilla gorilla beringei). - Primates 35: 35-47.

Watts, D. (2000). Causes and consequences of variation in male mountain gorilla life histories and group membership. - In: Primate males (Kappeler, P.M., ed.). Cambridge University Press, Cambridge, p. 169-179.

Westneat, D.F. \& Stewart, I.R.K. (2003). Extra-pair paternity in birds: causes, correlates, and conflict. - Annu. Rev. Ecol. Evol. Syst. 34: 365-396.

Wong, S.N.P., Saj, T.L. \& Sicotte, P. (2006). Comparison of the habitat quality and diet of Colobus vellerosus in forest fragments in Ghana. - Primates 47: 365-373.

Wong, S.N.P \& Sicotte, P. (2006). Population size and density of Colobus vellerosus at the Boabeng-Fiema Monkey Sanctuary and surrounding forest fragments in Ghana. - Am. J. Primatol. 68: 465-476.

Young, A.J., Spong, G. \& Clutton-Brock, T. (2007). Subordinate male meerkats prospect for extra-group paternity: alternative reproductive tactics in a cooperative mammal. Proc. Roy. Soc. Lond. B: Biol. 274: 1603-1609. 